\title{
On Growth
}

\author{
M. K. Heinemann, Editor-in-Chief, The Thoracic and Cardiovascular Surgeon
}

Thorac Cardiovasc Surg Rep 2012;1:3.

"Growth is exciting; growth is dynamic and alarming."1

Financial analysts love growth: indices, values, production numbers, profits - it is always a supposedly good sign if those things go up. ${ }^{2}$ Inhabitants of big cities are not so sure about the meaning of growth. Try finding a parking space in New York City. As so often in life, there are two sides to the medal.

The Thoracic and Cardiovascular Surgeon shows constant growth in the number of manuscripts newly submitted each year. From 2009 until 2012 there has been an increase of more than $30 \%$. This may be the dream of a CFO or shareholder; an editor, however, has to contemplate the parking space side of things too. The print version of a journal is clearly defined: $X$ pages times $Y$ volumes per year, that's it. For a journal still believing in print, as this one does, one either has to increase the page numbers (uneconomical) or cut down in selection (cruel) in order to avoid inadequate waiting times. eFirst publication solved only part of our problem. Whereas authors are generally satisfied when they get their DOI number which makes a paper citable, the more conservative reader who pours a good glass of something and then leans back in an armchair to skim through the pages of a favourite journal, may get irritated by the bibliographic data showing that many articles were accepted a year ago.

With Germans being the masters of compromise, we have now come up with a solution you are currently holding in your hands: The Thoracic and Cardiovascular Surgeon Reports. The case reports, an immensely popular category both for authors and readers, have been outsourced (to stay with business terminology). From now on a case report must be submitted through a separate website. Reviewer selection and peer review process will be coordinated by the new editor Andreas Böning, and the final decision about acceptance or rejection will be agreed upon by both him and the Editor-in-Chief of the sister (or should one say: mother ?) journal. After acceptance the author will be prompted to pay a submission fee in order to have the article published on an Open Access platform. Open Access in our case means that the manuscript will be professionally copy-edited by Thieme Publishers and then be made freely available for everybody with an internet access to read. No journal subscription is needed. About twice a year, a special print version of the collected case reports will be print published and mailed out to all subscribers of The Thoracic and Cardiovascular Surgeon.

We hope that this approach will be attractive for several reasons: It should allow us to accept more case reports, the category with the highest rejection rate so far. The same quality standards will apply, of course - we can simply be more generous because there are no page restraints. The reports will be out in the world very quickly. This is of essence for this type of publication, which is generally read a lot, but rarely cited. ${ }^{3}$ And finally the main journal will have more printing space for the more substantial publications.

The quintessence of economics remains: "There is no such thing as a free lunch." Publishing costs money and somebody has to provide it. In the classic subscription model it is the reader, in the Open Access world it is the author who wants to get a message across to everybody fast. We believe that our pricing is fair, even very competitive. Grant supplying institutions and universities, which seem to be increasingly in favour of Open Access models for various reasons, already include publication costs in their calculations, and there exists a list of countries in need for which publishers will commonly waive the fees. Thus, money should not really be a problem, although psychologically it always is. Very low- or even no-cost publications therefore keep invading the market, but generally have severe drawbacks if looked at closely. The group bringing The Thoracic and Cardiovascular Surgeon Reports to you does appreciate the price difference between a vintage Barolo and a two-litre bottle of Valpolicella. They would always go for the former. Cheers.

\section{References}

1 Sackville-West V In: Twelve Days: an account of a journey across the Bakhtiari Mountains of South-western Persia. Garden City, NY, USA: Doubleday Doran; 1928

2 Acemoglu D. Introduction to Modern Economic Growth. Princeton, NJ, USA: Princeton University Press; 2008

3 Heinemann MK. Cold Cases. Thorac Cardiovasc Surg 2011;59: $131-132$ (c) 2012 Georg Thieme Verlag KG Stuttgart · New York
DOI http://dx.doi.org/ $10.1055 / \mathrm{s}-0032-1331586$. ISSN 2194-7635. 